\title{
Spontaneous migration into the stomach and out of the intestine, as late complication of a gastric band
}

\author{
Mark W L van Geffen, ${ }^{1}$ Jan Willem A Straathof, ${ }^{2}$ Arijan A P M Luijten ${ }^{3}$
}

'Internal Medicine, Maxima Medisch Centrum, Veldhoven, The Netherlands

${ }^{2}$ Gastroenterology, Maxima Medisch Centrum, Veldhoven, The Netherlands

${ }^{3}$ Surgery, Maxima Medisch Centrum, Veldhoven, The Netherlands

\section{Correspondence to} Dr Mark W L van Geffen, markvgeffen@yahoo.com

Accepted 24 June 2018

\section{DESCRIPTION}

A 45 -year-old woman with morbid obesity (body mass index $44 \mathrm{~kg} / \mathrm{m}^{2}$ ) presented to the emergency department with severe abdominal pain, nausea, vomiting and no defaecation. She had a laparoscopic adjustable gastric banding (LAGB) inserted elsewhere in 2006. No data or follow-up was performed postoperatively. A CT scan demonstrated a perforated LAGB through the gastric antrum (figure 1). Furthermore the connecting tube perforated the small intestine at the level of the proximal part of the jejunum with a partially intraluminally positioned banding (figure 2), causing prestenotic dilatation of the jejunum (figure 3). An upper gastrointestinal endoscopy confirmed an intact port site with a connected tube and migration and perforation of the band into the jejunum with an erosion of the gastric (figure 4) and duodenal wall. At closer inspection of the port site and connecting tube, we observed a high level of traction on the banding (figure 5). LAGB is a common bariatric procedure performed for the treatment of morbid obesity and is a

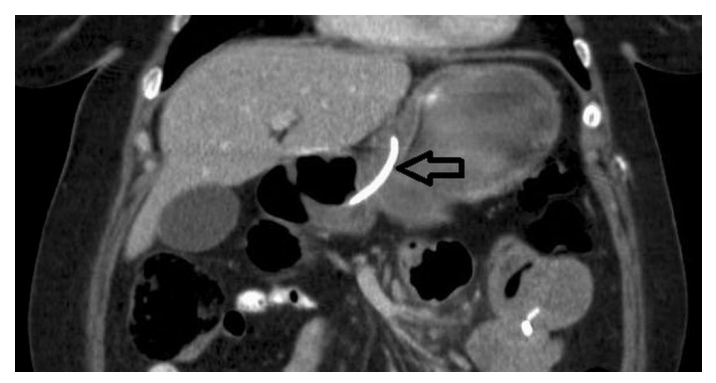

Figure 1 Laparoscopic adjustable gastric band perforating the gastric wall into the antrum.

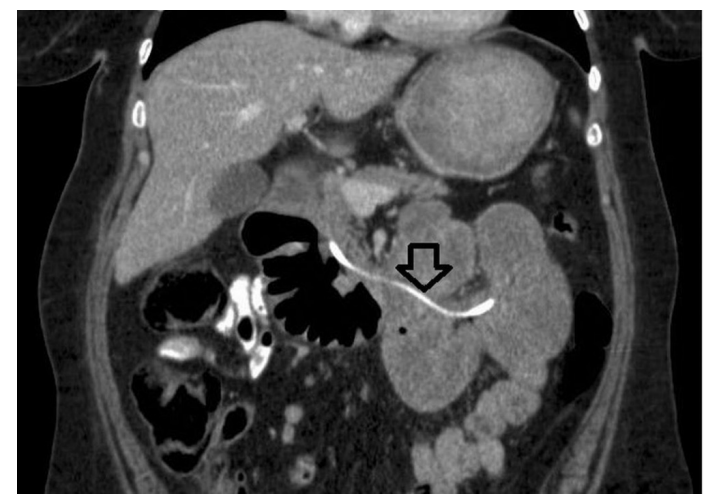

Figure 2 Laparoscopic adjustable gastric band positioned at the level of the duodenum into the proximal jejunum.

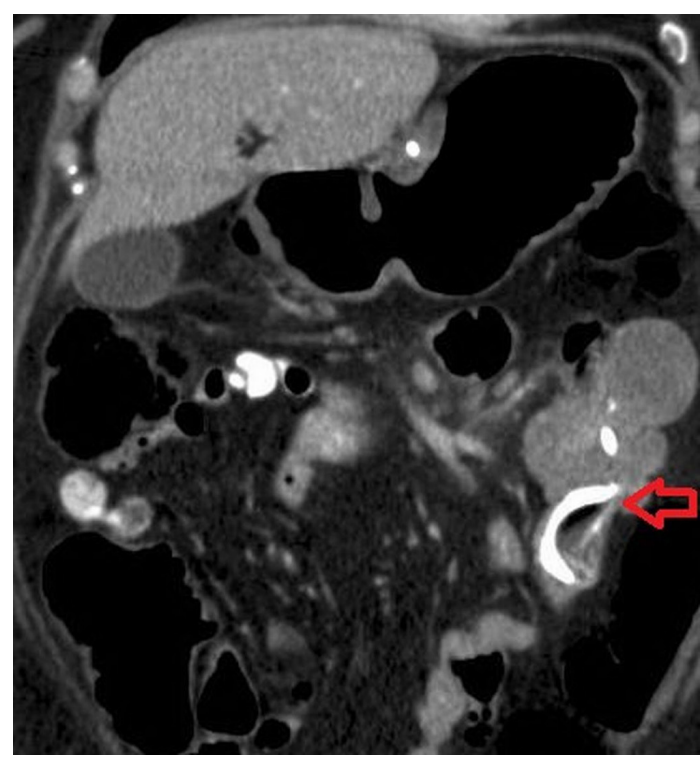

Figure 3 Laparoscopic adjustable gastric band positioned intraluminally at the level of the proximal jejunum causing prestenotic dilatation of the jejunum.

restrictive procedure that compartmentalises the upper stomach by placing a tight, adjustable prosthetic band around the entrance of the stomach. Clinical diagnosis of postoperative complications is difficult because symptoms are often non-specific or even absent. Complications can be related either to the band such as slippage, erosion and pouch dilatation, or due to the connecting tube such as infection, disconnection or dislocation and migration. ${ }^{1}$ Band migration into the gastric wall is a well-known postoperative complication, connecting tube migration into the intestinal lumen is very rare though. ${ }^{2}$ A few cases have been described due to tube migration into the jejunal lumen or colonic lumen. ${ }^{2-4}$ In our case the tube

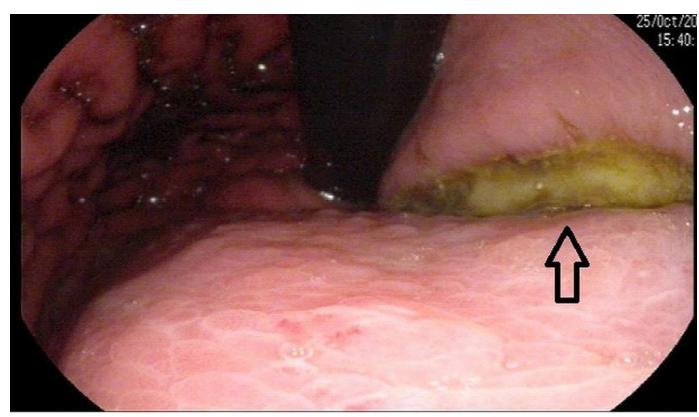

Figure 4 Erosion of the gastric wall caused by a laparoscopic adjustable gastric band. 


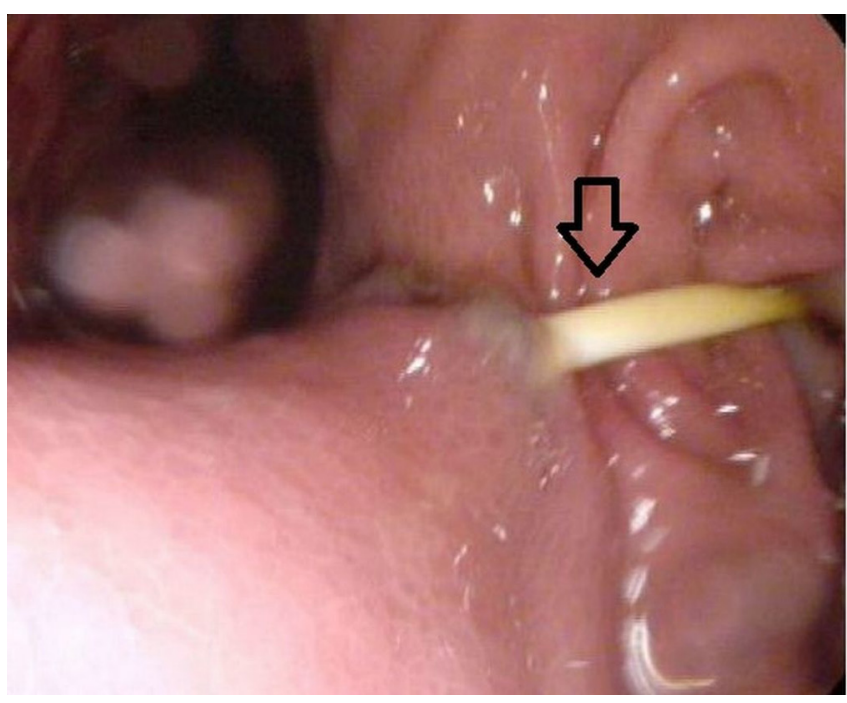

Figure 5 Close inspection of the port site and connected tube with a high level of traction on the laparoscopic adjustable gastric band.

migrated into the jejunal wall causing obstruction at the level of the proximal jejunum without disconnection from the port after a previous erosion and perforation of the gastric and duodenal wall. CT scan as well as endoscopy seem to be essential diagnostic tools in the evaluation of abdominal pain and obstruction due to band migration in order to observe previous erosion or perforation of the gastric or intestinal lumen. These complications should be considered even after many years of initial procedure. During an emergency laparotomy a gastrojejunal anastomosis was made after an intestinal resection of the distal duodenum and proximal jejunum. After 6 months an

\section{Learning points}

- Complications such as erosion, perforation and migration of a laparoscopic adjustable gastric band (LAGB) should be carefully considered even after many years of initial procedure.

- CT imaging as well as endoscopy can play a pivotal role in the diagnosis of a complication of an LAGB.

elective open gastric bypass was done, and 1 month later the patient regained a normal diet.

Contributors All authors have contributed to the planning, conduct and reporting of the work described in the article. The first and corresponding author MWLVG did most of the work in planning and writing of the case description, and he formatted the images as presented in the manuscript. The second author JWS as well as the third author AAPML contributed to correcting and discussing the case description.

Funding The authors have not declared a specific grant for this research from any funding agency in the public, commercial or not-for-profit sectors.

Competing interests None declared.

Patient consent Obtained.

Provenance and peer review Not commissioned; externally peer reviewed.

\section{REFERENCES}

1 O'Brien PE, MacDonald L, Anderson M, et al. Long-term outcomes after bariatric surgery: fifteen-year follow-up of adjustable gastric banding and a systematic review of the bariatric surgical literature. Ann Surg 2013;257:87-94.

2 Navarra G, Musolino C, Centorrino T, et al. Perforation of an adjustable gastric banding connecting tube into distal transverse colon with intra-luminal migration. Obes Surg 2009;19:125-7.

3 Zengin K, Sen B, Ozben V, et al. Detachment of the connecting tube from the port and migration into jejunal wall. Obes Surg 2006;16:206-7.

4 Hartmann J, Scharfenberg M, Paul M, et al. Intracolonic penetration of the laparoscopic adjustable gastric banding tube. Obes Surg 2006;16:203-5.

Copyright 2018 BMJ Publishing Group. All rights reserved. For permission to reuse any of this content visit

http://group.bmj.com/group/rights-licensing/permissions.

BMJ Case Report Fellows may re-use this article for personal use and teaching without any further permission.

Become a Fellow of BMJ Case Reports today and you can:

- Submit as many cases as you like

- Enjoy fast sympathetic peer review and rapid publication of accepted articles

- Access all the published articles

- Re-use any of the published material for personal use and teaching without further permission

For information on Institutional Fellowships contact consortiasales@bmjgroup.com

Visit casereports.bmj.com for more articles like this and to become a Fellow 